\title{
Methodology for the systematic design of conical plain bearings for use as main bearings in wind turbines
}

\author{
Amadeus Rolink ${ }^{1}$ (D) Georg Jacobs ${ }^{1} \cdot$ Tim Schröder $^{1}$ - Dennis Keller ${ }^{1} \cdot$ Timm Jakobs $^{1}$ • Dennis Bosse ${ }^{1}$ • \\ Jochen Lang ${ }^{2}$ Gunter Knoll ${ }^{2}$
}

Received: 1 December 2020 / Accepted: 18 February 2021 / Published online: 8 March 2021

(c) The Author(s) 2021

\begin{abstract}
With the possibility to replace sliding segments on the tower without disassembling the drivetrain, the use of segmented plain bearings with conical sliding surfaces as main bearing in wind turbines has a great potential to reduce the maintenance costs and thus the levelized cost of energy (LCOE). Furthermore, the short axial design leads to lower investment costs. Since this design is totally new and no design guidelines are available so far, the objective of this paper is to investigate the influence of the geometric parameters on the hydrodynamic pressure distribution of the bearing. In this context a parameter screening is performed using a suitable test field according to Plackett and Burman in order to determine the most relevant parameters. With the help of the simulations carried out after this test field, correlations between the geometric parameters and the hydrodynamic pressure distribution are evaluated. To be able to quantitatively analyze the three-dimensional pressure distribution, several key values are defined in this paper that describe the pressure distribution. The content of this paper is part of a methodology with the goal of developing a design guideline for conical plain bearings.
\end{abstract}

\section{Methodik zur systematischen Auslegung von konischen Gleitlagern für den Einsatz als Hauptlager in Windenergieanlagen}

\section{Zusammenfassung}

Segmentierte Gleitlager mit konischen Gleitflächen besitzen ein großes Potential die Instandhaltungskosten und die Stromgestehungskosten einer Windenergieanlage zu senken, da im Schadensfall die Gleitsegmente auf dem Turm ausgetauscht werden können. Zudem wirkt sich die kurze axiale Baulänge positiv auf die Investitionskosten aus. Da die existierenden Normen für die Gleitlagerauslegung auf dieses neue Lagerungskonzept nicht anwendbar sind, muss eine Auslegungsmethodik für solche Lager entwickelt werden. Vor diesem Hintergrund ist das Ziel dieses Papers die relevanten geometrischen Einflussgrößen auf die hydrodynamische Druckverteilung zu bestimmen. Hierzu wird ein simulatives Parameter-Screening unter Verwendung eines Plackett-Burman Testfeldes durchgeführt und passende Zielgrößen für die quantitative Beschreibung der dreidimensionalen Druckverteilung abgeleitet. Das in diesem Paper durchgeführte Parameter-Screening ist die Grundlage für die weitergehende Entwicklung einer Auslegungsmethodik für konische Gleitlager.

\section{Motivation and objectives}

Amadeus Rolink

amadeus.rolink@cwd.rwth-aachen.de

Jochen Lang

jochen.lang@ist-aachen.com

1 Chair for Wind Power Drives, RWTH Aachen University, Campus-Boulevard 61, 52074 Aachen, Germany

2 IST mbH, Schloss-Rahe-Str. 12, 52072 Aachen, Germany
For many years now, the trend towards larger wind turbines can be observed. In 2018, GE presented the Haliade X, the largest wind turbine to that point with a rated power of $12 \mathrm{MW}$ and a rotor diameter of $220 \mathrm{~m}$ [1]. In 2020, Siemens Gamesa presented the SG 14-222 DD, a turbine with up to $15 \mathrm{MW}$ power and a rotor diameter of $222 \mathrm{~m} \mathrm{[2].} \mathrm{The}$ development of such large wind turbines with big main shaft diameters sets high demands on the main bearings. 
As the size of the turbines increases, the assembly becomes more and more a driver of costs, because the needed equipment is limited available. Especially the installation of offshore turbines, where big crane ships are needed, is extremely expensive and has a significant effect on the levelized costs of energy (LCOE) [3]. For this reason, a failure of the currently used rolling bearings of the main bearing arrangement can have a serious impact on the economic efficiency of the turbine, as in this case the drivetrain needs to be disassembled. In this context, a change of technology to segmented plain bearings offers two major advantages over roller bearings. On the one hand, due to the segmented design, plain bearings have no size limitations and can be used in future turbines, unlike roller bearings which require fully enclosed bearing rings. On the other hand, in case of a bearing failure the single segments can be exchanged on the tower with onboard equipment and without having to disassemble the drivetrain.

Of the main bearing concepts used today, the moment bearing is the lightest and most compact. Therefore, in a former research project conducted at CWD an innovative plain bearing concept, called "FlexPad", with conical sliding surfaces and designed as moment bearing was developed and experimentally validated. The design is similar to the main bearing arrangement with tapered roller bearings and it was proven that such an arrangement also can be realized with plain bearings with conical sliding surfaces [4-6]. The FlexPad concept combines the advantages of a segmented plain bearing with those of a compact drivetrain and is applicable for geared turbines as well as for direct drive turbines.

However, the existing design standards for plain bearing design are limited to axial and radial plain bearings and there are no guidelines for conical plain bearings. In comparison to established axial and radial plain bearings the geometry of a conical plain bearing is more complex and the effect of the geometric parameters on the load distribution and the hydrodynamic pressure build-up is unknown. Therefore, the main objective of this paper is to identify the relevant geometric parameters. For this purpose, a parameter screening with use of a Plackett-Burman test field is performed. With the results of the parameter screening a qualitative evaluation of correlations is possible and the most relevant parameters can be identified.

\section{Conical plain bearing concept "FlexPad"}

In this section a brief overview of the FlexPad plain bearing concept is presented. This bearing concept was developed and validated in the previous research project "WEAGLiTS". The aim of this project was to develop a compact sliding bearing with exchangeable sliding segments and to prove the functionality in a prototype test. For further in- formation and more details see the cited publications [4-7]. Based on these results, the focus of the follow-up project is on the optimization and broader investigation of the bearing concept in order to derive a design methodology.

The FlexPad bearing was designed as moment bearing in order to carry the 5 degree of freedom (DOF) loads (axial and radial forces and bending moments) at one bearing point, which allows to realize a very compact drivetrain (see Fig. 1a,b). The combination of a general bearing clearance and an inlet contour on each pad ensures a convergent gap for the hydrodynamic pressure build-up.

While designing such a bearing, it quickly becomes evident that due to the high bending moments caused by the turbulent wind field and the rotor weight, the shaft tilts within the bearing clearance. In case of a stiff bearing, locally very high pressures occur. This phenomenon is called edge loading and leads to a quick failure of the bearing if no countermeasures are taken. In order to prevent edge loading, the sliding segments are connected to the bearing housing via a double flexible support structure (Fig. 1c). Compared to other methods to prevent this effect (like adjustment of the pads via tilting joints), this design is less prone to wear as it uses only the structural elasticity to ensure the alignment of the segments to the tilting shaft. Fig. 2 shows the functionality of the double flexible support structure. Due to the special geometry the loaded pad can perform a parallel displacement, which prevents edge loading.

\section{Approach}

In this section the approach for the identification of the relevant parameters is presented. First, an overview of the simulation process is provided and why it was automatized. Furthermore, the output values are defined and finally the geometric parameters and the test field for the parameter screening with its properties are presented.

\subsection{Automatized simulation models}

To calculate the hydrodynamic pressure distribution and other output variables, elasto-hydrodynamic (EHD) simulations are performed. Elasto-hydrodynamic means that the shaft and the bearing are modelled as flexible bodies and thus the elastic deformation is taken into account when calculating the pressure distribution. As studies of Schröder et al., Thomsen et al. and Witter [5, 8, 9] have shown, the elastic deformation of the bearing has an important influence on the pressure distribution. For the investigations made in this paper, an EHD-model with flexible sliding segments, a flexible shaft and a flexible housing is built using the software IST First. This ensures that the deformation of 

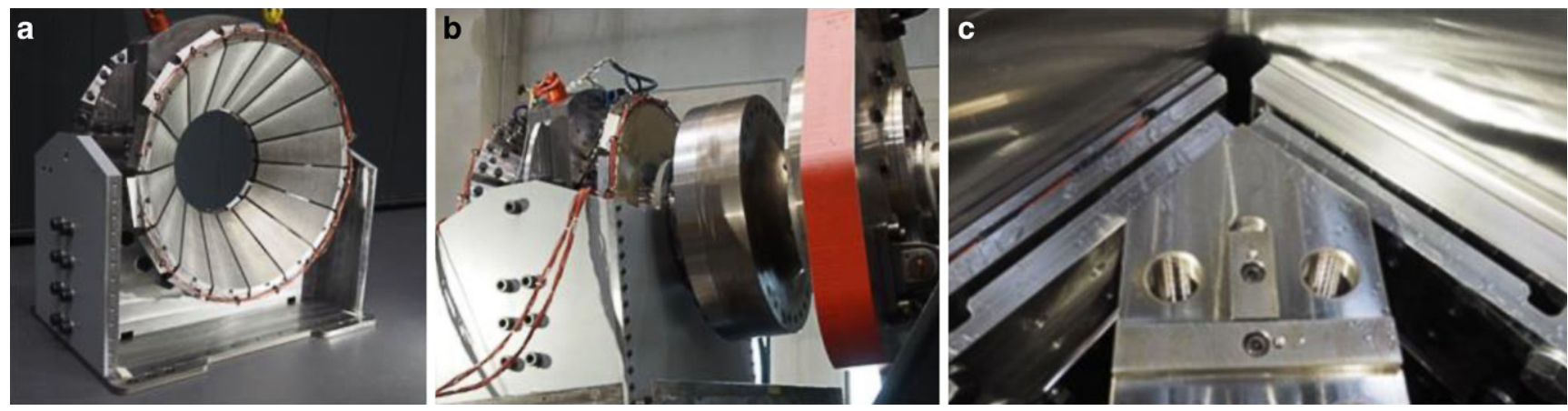

Fig. 1 a FlexPad bearing concept, $\mathbf{b}$ Experimental validation on test bench, $\mathbf{c}$ Flexible segment support structure
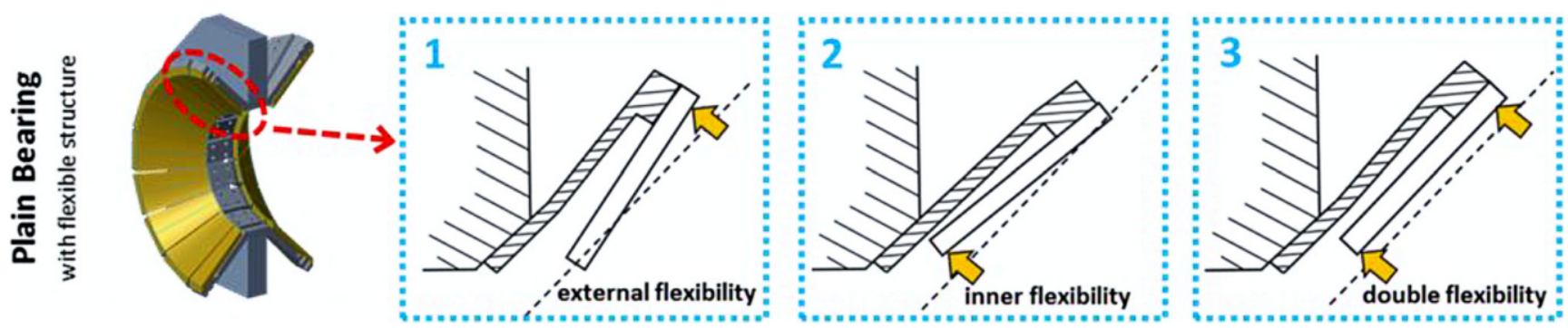

Fig. 2 Functionality of the double flexibility of the FlexPad's segment support structure

the surrounding structure and the double flexibility shown in Fig. 2 is considered. The simulation model has been validated with experimental results from a prototype test of a previous research project [5]. To conduct such a simulation, the following modelling steps are necessary:

1. Setup of the CAD-model with the correct geometric parameters

2. Modelling of the bearing and the shaft in a FE software including geometry import, definition of constraints and mesh generation

3. Conduction of modal reduction to decrease the degrees of freedom

4. Setup of the EHD model and conduction of simulation

5. Post processing of the results

The manual execution of the modelling and the simulation process is very time consuming due to both the model setup and the large computation times of several hours. In addition, in case of a manual model setup the whole process is error prone. In order to avoid errors and significantly reduce the modelling time, the process was automated for this study. Thereby the input parameters are entered by the user in a table, which functions as "single point of truth" for the model setup. The whole following process of the geometry generation, modelling as FE model, modal reduction and EHD model setup and simulation is executed automatically. With the help of the automatized simulation process, the required simulations can be performed much more efficiently. The time required for a simulation (model setup and computation time) is reduced from about 10 to only $3 \mathrm{~h}$. This time saving is mainly based on the reduced modelling effort. In addition, the computation times for the modal reduction and EHD simulation were reduced, amongst other reasons, due to a more efficient meshing.

\subsection{Definition of quantifiable key values}

An important quantity for the design of a plain bearing is the pressure distribution. Fig. 3a shows the geometry of a FlexPad bearing designed for a wind turbine with a rated capacity of $1 \mathrm{MW}$ and the calculated three-dimensional pressure distribution (Fig. 3b) for a static 5 DOF load case. This 5 DOF load case represents the $90 \%$ percentiles of the turbine loads during the power production operation mode (DLC 1.1) and is used as input load case for the simulations made in this paper. Fig. $3 \mathrm{~b}$ reveals that due to the axial force, the front cone is uniformly loaded. In contrast, the back cone is only loaded in a small area, caused by the combined radial force and bending moments. To be able to systematically evaluate the pressure distribution of a bearing design and compare it with results of other bearing variants, quantifiable key values must be defined that describe the pressure distribution. A suitable and important value for the bearing design is the maximum pressure on the most highly loaded pad, because this value should not exceed the strength of the bearings pad material. Another important value is the position of the pressure maximum along the pad length, since if the pads are loaded on the 


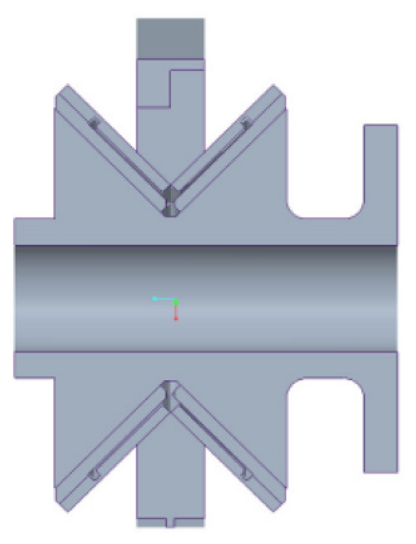

b

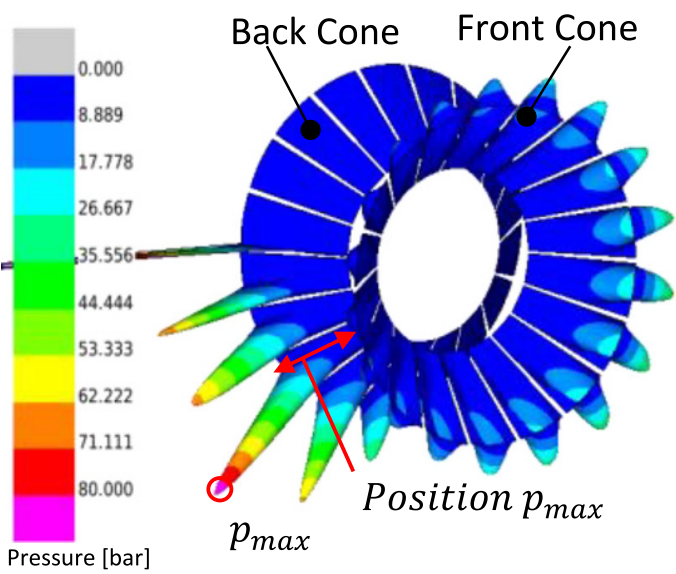

C Pressure Area Ratio $\left(p_{\min }=1\right.$ bar $)$

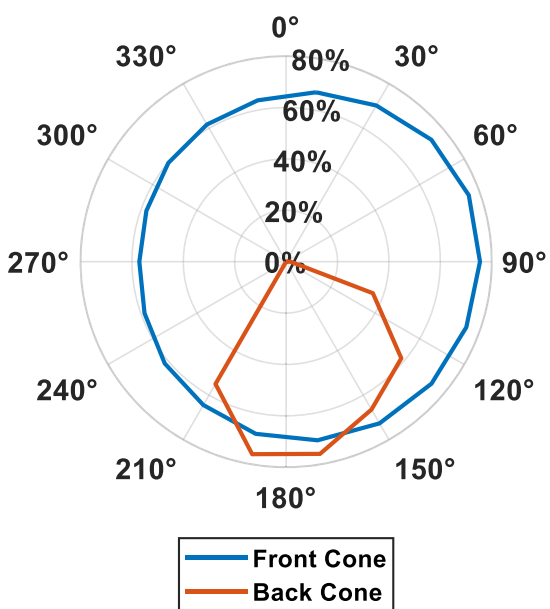

Fig. 3 a Geometry of a FlexPad variant, b Three-dimensional pressure distribution, c Pressure area ration for front and back cone

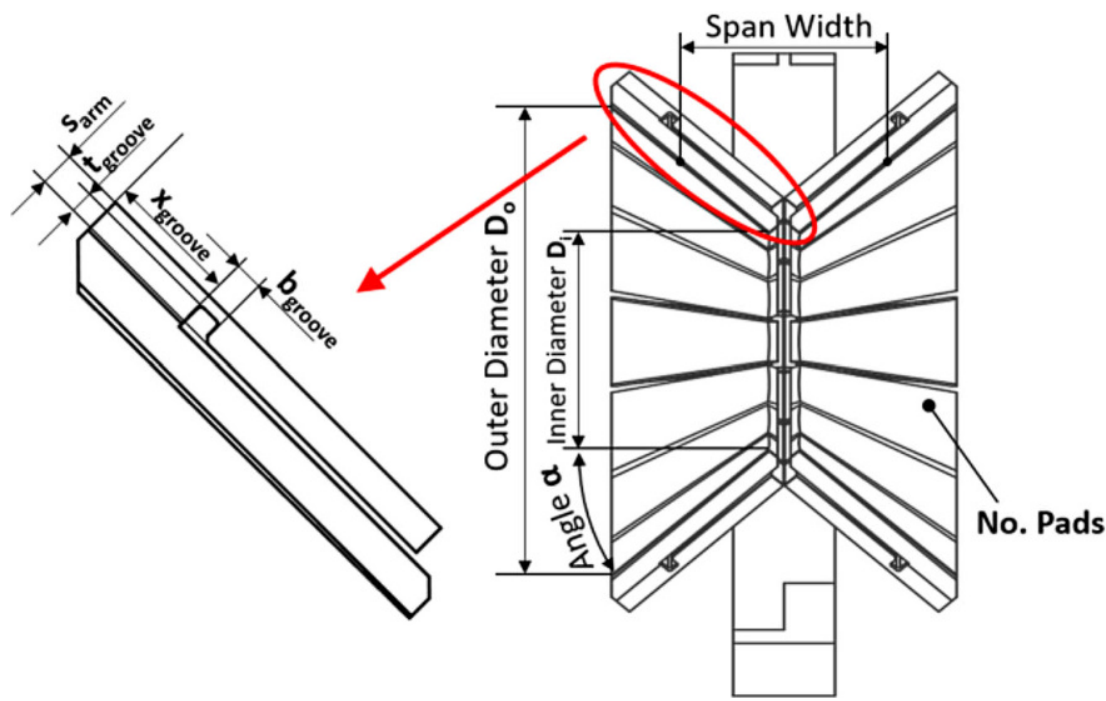

\begin{tabular}{|l|l|}
\hline Global parameters & \\
\hline $\boldsymbol{\alpha}$ & Cone Angle \\
\hline $\mathbf{D}_{\mathbf{0}}$ & Outer Diameter \\
\hline $\mathbf{D}_{\mathbf{i}}$ & Inner Diameter \\
\hline Span Width & Supporting Span \\
\hline No. Pads & Number of Pads \\
\hline Flexible Support & \\
\hline $\mathbf{S}_{\text {arm }}$ & Arm Thickness \\
\hline $\mathbf{b}_{\text {groove }}$ & Groove Width \\
\hline $\mathbf{t}_{\text {groove }}$ & Groove Depth \\
\hline $\mathbf{x}_{\text {groove }}$ & Groove Position \\
\hline Other & \\
\hline $\boldsymbol{\Psi}$ & Bearing Clearance \\
\hline
\end{tabular}

Fig. 4 Geometric parameters describing a conical FlexPad bearing

outer edge, the risk of edge loading increases. To visualize the loaded zone of the bearing, the pressure area ratio is calculated (area of the pad that carries at least a pressure of 1 bar in relation to the total pad area) and is shown for the front and the back cone in Fig. 3c. The evaluation example shows that for all of the pads of the front cone $60-80 \%$ of the surface is loaded with a hydrodynamic pressure greater than 1 bar, while at the back cone only the bottom pads are loaded, due to the dominant bending moments. The following analysis of the simulation results focusses on these key values.

\subsection{Test field for parameter screening}

As mentioned before, the geometry of a conical plain bearing is a lot more complex than the geometry of commonly used axial and radial plain bearings. In case of a radial bearing, the geometry can be described by just two parameters, namely the diameter and the bearing width. The following figure shows the parameters that describe the geometry of a conical FlexPad bearing. The parameter set is divided in different groups, namely the global parameters that define the size and the shape of the bearings and the parameters that define the geometry of the flexible support structure and thus the alignment of the pads. It must be mentioned that the parameter $\mathrm{x}_{\text {groove }}$ on the one hand defines the position of the groove and on the other hand the size of the connection area between the arm and the pad. The bearing clearance is defined for the mean diameter of the bearing cones.

The aim of this study is to perform a parameter screening with as few simulations as possible and thus to determine 


\begin{tabular}{|c|c|c|c|c|c|c|c|c|c|c|}
\hline Simulation & alpha $\left[{ }^{\circ}\right]$ & $D_{o}[\mathrm{~mm}]$ & $D_{i}[\mathrm{~mm}]$ & $\begin{array}{l}\text { Supporting } \\
\text { Span [mm] }\end{array}$ & $\begin{array}{c}\text { No. Pads } \\
{[-]}\end{array}$ & $S_{\text {arm }}[\mathrm{mm}]$ & $\begin{array}{c}B_{\text {groove }} \\
{[\mathrm{mm}]}\end{array}$ & $\begin{array}{c}T_{\text {groove }} \\
{[\mathrm{mm}]}\end{array}$ & $\begin{array}{c}x_{\text {groove }} \\
{[\mathrm{mm}]}\end{array}$ & $\begin{array}{c}\text { Bearing } \\
\text { Clearance } \\
{[\% \circ]}\end{array}$ \\
\hline 1 & $\underline{50}$ & $\underline{488}$ & $\underline{237}$ & 450 & $\underline{18}$ & $\underline{28.5}$ & $\underline{25}$ & $\underline{19.1}$ & $\underline{120}$ & $\underline{1.4}$ \\
\hline 2 & $\underline{40}$ & $\underline{488}$ & $\underline{187}$ & 450 & $\underline{18}$ & $\underline{28.5}$ & $\underline{15}$ & $\underline{15.1}$ & 80 & 1.4 \\
\hline 3 & 40 & $\underline{438}$ & $\underline{237}$ & 400 & $\underline{18}$ & $\underline{28.5}$ & $\underline{25}$ & $\underline{15.1}$ & $\underline{80}$ & $\underline{1}$ \\
\hline 4 & $\underline{50}$ & $\underline{438}$ & $\underline{187}$ & 450 & $\underline{14}$ & $\underline{28.5}$ & $\underline{25}$ & $\underline{19.1}$ & $\underline{80}$ & $\underline{1}$ \\
\hline 5 & $\underline{40}$ & $\underline{488}$ & $\underline{187}$ & 400 & $\underline{18}$ & $\underline{24.5}$ & $\underline{25}$ & $\underline{19.1}$ & $\underline{120}$ & $\underline{1}$ \\
\hline 6 & $\underline{40}$ & $\underline{438}$ & $\underline{237}$ & 400 & $\underline{14}$ & $\underline{28.5}$ & $\underline{15}$ & $\underline{19.1}$ & $\underline{120}$ & $\underline{1.4}$ \\
\hline 7 & $\underline{40}$ & 438 & $\underline{187}$ & 450 & $\underline{14}$ & $\underline{24.5}$ & $\underline{25}$ & $\underline{15.1}$ & $\underline{120}$ & $\underline{1.4}$ \\
\hline 8 & $\underline{50}$ & $\underline{438}$ & $\underline{187}$ & 400 & $\underline{18}$ & $\underline{24.5}$ & $\underline{15}$ & $\underline{19.1}$ & 80 & $\underline{1.4}$ \\
\hline 9 & $\underline{50}$ & $\underline{488}$ & $\underline{187}$ & 400 & $\underline{14}$ & $\underline{28.5}$ & $\underline{15}$ & $\underline{15.1}$ & $\underline{120}$ & $\underline{1}$ \\
\hline 10 & $\underline{50}$ & $\underline{488}$ & $\underline{237}$ & 400 & $\underline{14}$ & $\underline{24.5}$ & $\underline{25}$ & $\underline{15.1}$ & $\underline{80}$ & 1.4 \\
\hline 11 & $\underline{40}$ & $\underline{488}$ & $\underline{237}$ & 450 & $\underline{14}$ & $\underline{24.5}$ & $\underline{15}$ & $\underline{19.1}$ & $\underline{80}$ & $\underline{1}$ \\
\hline 12 & $\underline{50}$ & $\underline{438}$ & $\underline{237}$ & 450 & $\underline{18}$ & 24.5 & $\underline{15}$ & $\underline{15.1}$ & $\underline{120}$ & $\underline{1}$ \\
\hline
\end{tabular}

Fig. 5 Plackett-Burman test field for parameter screening

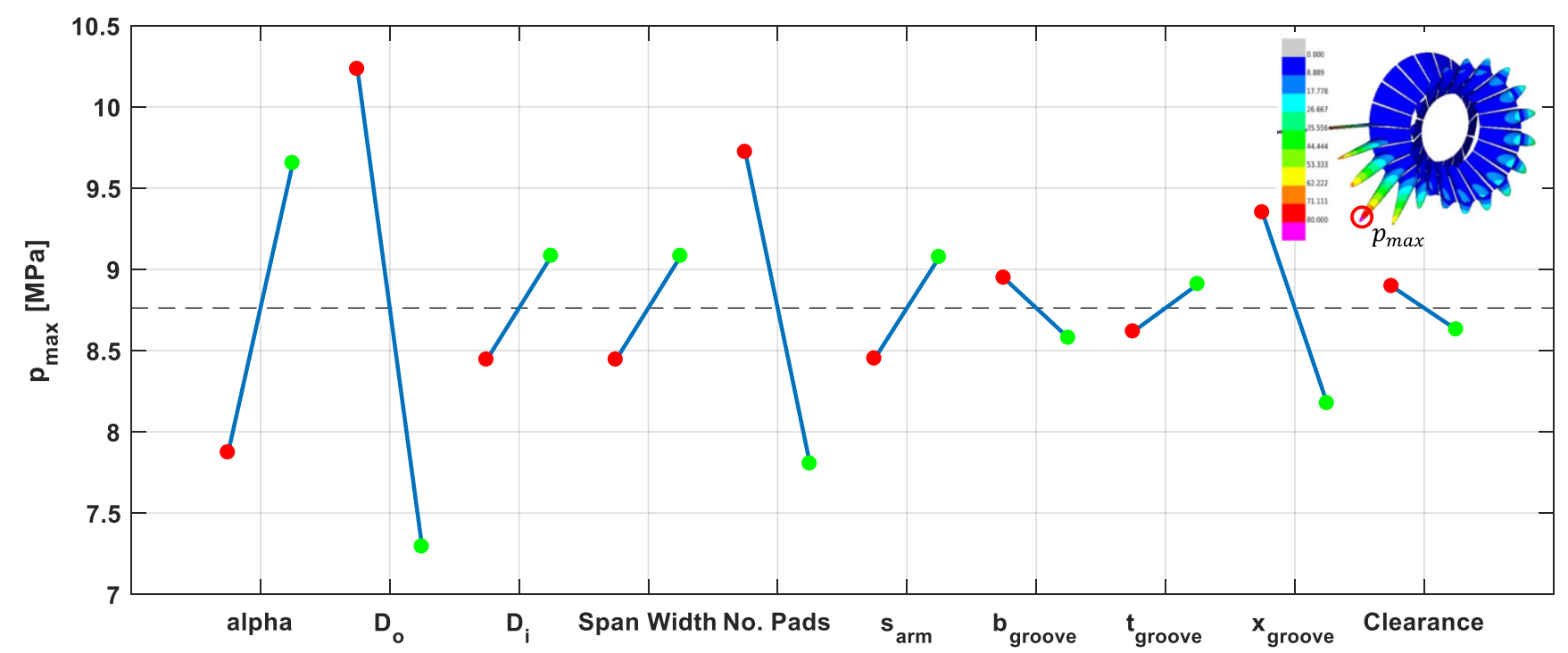

Fig. 6 Effect diagram for the output value $\mathrm{p}_{\max }$

the relevant parameters that have a significant influence on the key values. For this purpose a two-level test field defined by Plackett and Burman is used [10]. These test fields are characterized by a high efficiency. Already with very few experiments, results of the resolution class III can be achieved. This means that the main effects are confounded with two-way interactions (means that the effect of one parameter depends of the value of another parameter) but not with other main effects [11]. The high efficiency is very advantageous for the application described here, since the computing times of the simulations require several hours with a high demand of disk space. In addition, the attainable resolution of the results is sufficient for a qualitative evaluation. However, due to the high efficiency, only linear correlations can be resolved with this test field. Regarding the objective of determining the most relevant parameters, this is acceptable. For the parameters listed in Fig. 4, the fol- lowing field with a total of 12 simulations is used. Hereby the upper levels of the parameters are marked green and the lower levels red (see Fig. 5).

The lower and upper limits of the parameters were chosen considering geometrical restrictions. For instance, it is not possible to realize a flat cone angle with a short span width or to select an arm thickness smaller than the groove depth. Unlike the intuitive method of varying one parameter and keeping the others constant (one at a time), this test field ensures that the results do not depend on the initial geometry.

\section{Results}

As a result of the parameter screening, the effects strength on the key values are evaluated and presented in effect di- 


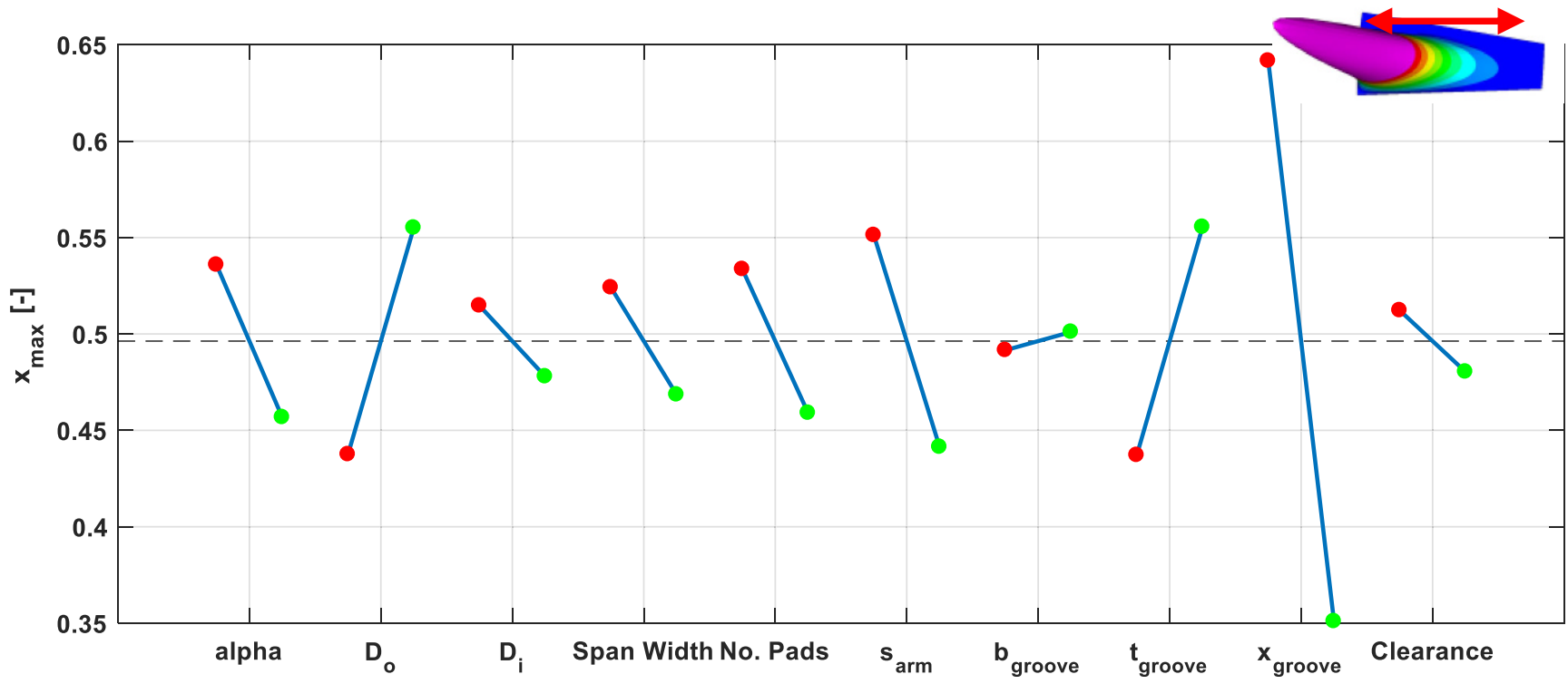

Fig. 7 Effect diagram for the output value position $p_{\max }$

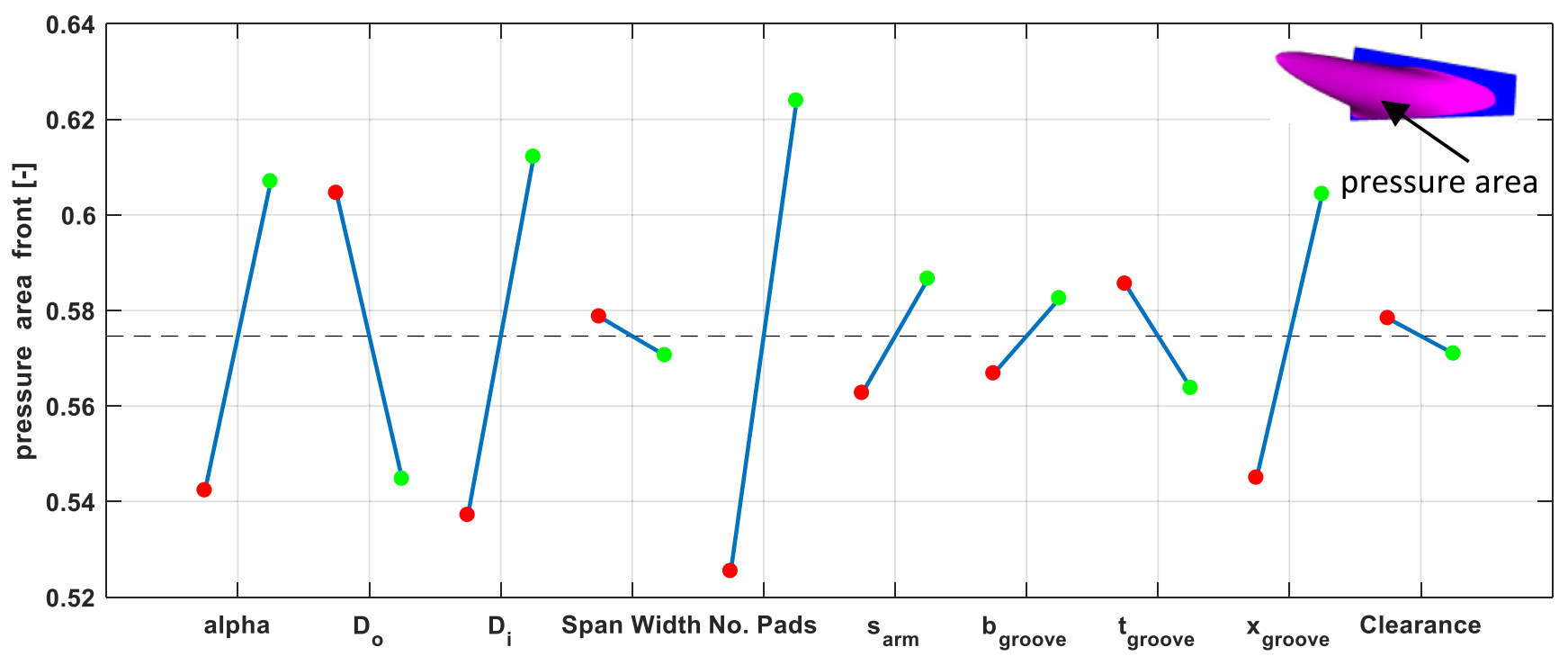

Fig. 8 Effect diagram for the mean pressure area ratio at the front cone

agrams. The focus here is on the maximum pressure, the position of the maximum pressure and the pressure area ratio of the front and the back cone.

\subsection{Parameter effects regarding maximum pressure}

Fig. 6 shows the results of the parameter screening for the output value maximum pressure on the most loaded pad in an effect diagram. On the horizontal axis, the investigated parameters are listed and on the vertical axis the respective key value. The red dots show the key values for the lower level and the green dots the key values for the higher level of the parameters. The dashed line represents the mean value of all simulations and the slope of the blue line between the red and the green point indicates the effect strength of the parameter.

It can be seen that the cone angle alpha, the outer diameter $\mathrm{D}_{\mathrm{o}}$, the number of Pads and the position of the groove $\mathrm{X}_{\text {groove }}$ have the greatest effect on the maximum pressure. The influence of the cone angle can be related to the fact that at a flatter cone angle, the resulting forces on the pads of the back cone (mostly caused by the dominant bending moments) are smaller and therefore smaller maximum pressures occur. Fig. 4 shows that a larger outer diameter $\mathrm{D}_{\mathrm{o}}$ leads to an increased sliding surface, thus the load is taken by a larger surface and consequently the maximum pressure decreases. In case of a lower number of pads, some pads in the loaded zone are only partially loaded and can- 
not perform a parallel displacement, what results in higher maximum pressures. The higher the value of $\mathrm{x}_{\text {groove }}$, the bigger is the connection area between the pad and the arm (see Fig. 4) and the higher is the inner stiffness of the flexible support structure. It seems that with a higher stiffness the pressure is more evenly distributed on the pad. This assumption will be confirmed by analyzing the results of the position of the maximum pressure and the pressure area ratios. In further investigations with a more detailed test field, this effect should be analyzed in more detail, since it is to be expected that if the value of $\mathrm{x}_{\text {groove }}$ is too high, the arm stiffness will become too large and edge loading will occur. It is interesting to see that the span width seems not to be a dominant parameter. This counteracts the assumption that with an increase span width the resulting pressure maximum should decrease. An explanation could be that in the investigated range the parameter has not a major influence. Another interesting conclusion is that the global parameters such as alpha, Do and the number of pads have a major influence on the peak pressure but the parameters with influence on the stiffness of the support structure have not a significant influence with exception of $\mathrm{x}_{\text {groove }}$.

\subsection{Parameter effects regarding the position of the maximum pressure}

Fig. 7 shows the results for the position of the pressure maximum. The values on the vertical axis are normalized to the pad length, since the pad lengths of the different variants are not constant. A value of 1 means that the pressure maximum is located on the outer edge of the pad and a value of -1 on the inner edge. A value of 0 means that the pressure maximum is located on the middle of the pad.

When looking on the effect plot for the position of the pressure maximum (Fig. 7), it can be seen that the position of the groove has the biggest influence. When increasing the value of $\mathrm{x}_{\text {groove }}$, the pressure maximum is more located on the middle of the pad. In this case the load is distributed over a larger area of the pads, what leads to a lower peak pressure. This observation is consistent with the result shown in Fig. 6.

It can be concluded that the parameters, that influence the stiffness of the pad support structure (e.g. $\mathrm{x}_{\text {groove }}, \mathrm{t}_{\text {groove }}$, $\left.\mathrm{S}_{\mathrm{arm}}\right)$, have a major influence and with these parameters the position of the maximum pressure can be adjusted. Here it is important to mention that the influence of the mesh density and the number of considered modes on the simulation results was investigated to ensure that the results are not distorted by inaccurate modeling.

\subsection{Parameter effects regarding the pressure area ratio at the front cone}

Fig. 8 shows the resulting effects for the mean pressure area ratio (area with a pressure of at least 1 bar related to the total area) of the pads of the front cone. The parameters with the highest effect are the cone angle alpha, the outer and inner diameter, the number of pads and $\mathrm{x}_{\text {groove. }}$. The effect of the cone angle can be explained by the fact that with a higher cone angle, the projected area in axial direction increases and the axial force is absorbed more evenly. Regarding the diameters, it can be said that the combination of a small outer diameter and a large inner diameter results in a smaller sliding surface. This smaller sliding surface is more evenly loaded.

If the load is distributed to a higher number of pads, these pads are individually more evenly loaded and due to their flexibility they can adjust better to the load case. This results in lower maximum pressure and corresponds with the observation made in Fig. 6. A look at $\mathrm{x}_{\text {groove }}$ confirms the assumption that a higher stiffness of the bearing support structure leads to a more even load distribution.

\subsection{Parameter effects regarding the pressure area ratio at the back cone}

Since only the bottom pads of the back cone are significantly loaded (see Fig. 3), only pads that are at least $20 \%$ loaded are included in the evaluation of the pressure area ratio. For these pads, an average value of the pressure area ratio is calculated.

Looking at the effect diagram for the pressure area ratio at the back cone (Fig. 9), the effects are very similar as for the front cone (Fig. 8). Again, the cone angle, the outer and inner diameter, the number of pads and $\mathrm{x}_{\text {groove }}$ have the greatest influence. The strength and direction of these effects can be traced back to the same dependencies as on the front cone.

At this point, the observation can be made that with a larger angle alpha, both the maximum pressure and the pressure area ratio increases. The same can be observed for a larger diameter or a smaller inner diameter. The reason for this depends on the fact that for a steeper inclination angle (or a smaller outer diameter or a larger inner diameter), the sliding surface decreases. On this smaller sliding surface, a more even pressure build-up takes place, resulting $s$ in higher pressure area ratio. However, the load must be absorbed on a smaller area, which results in higher maximum pressure.

The result that a larger arm thickness $s_{\text {arm }}$ leads to a higher maximum pressure and a higher pressure area ratio appears contradictory. The effect of the arm thickness cannot be analyzed completely independent in this study, since as men- 


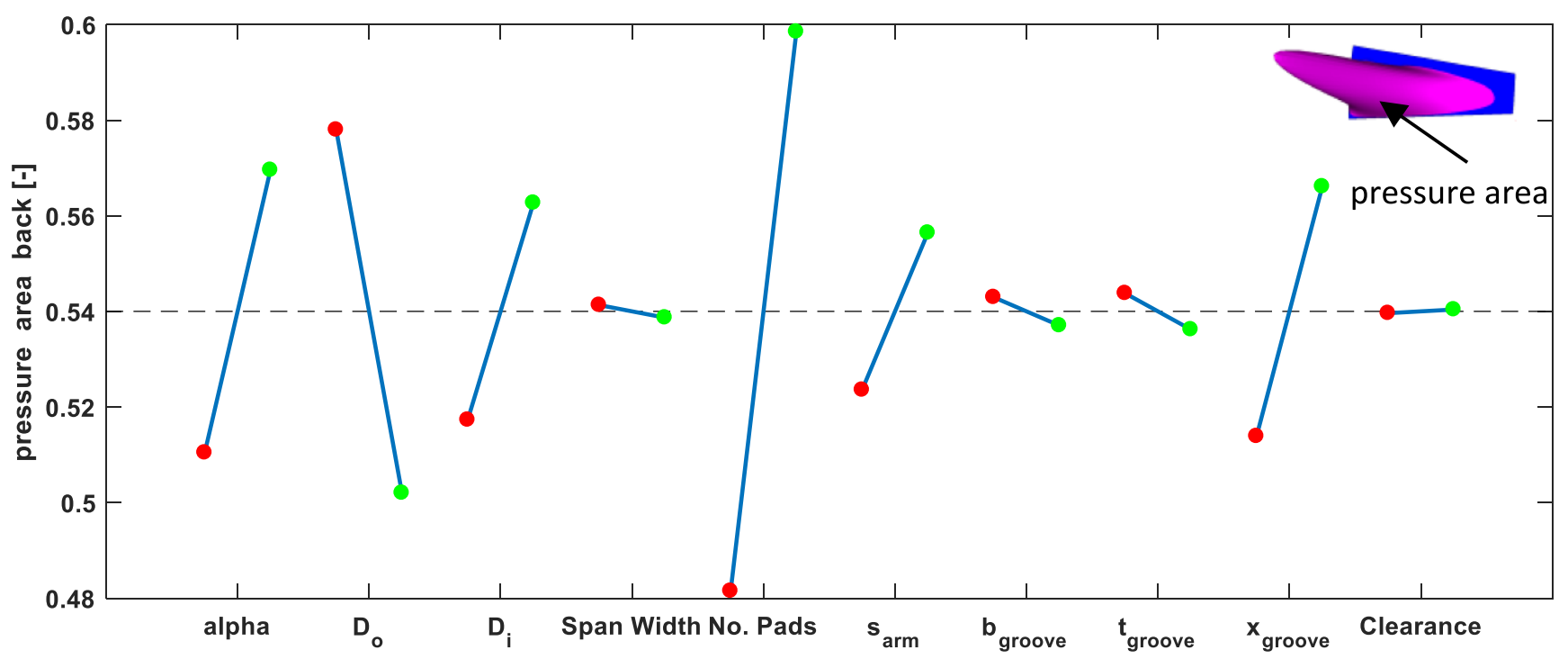

Fig. 9 Effect diagram for the mean pressure area ratio at the back cone

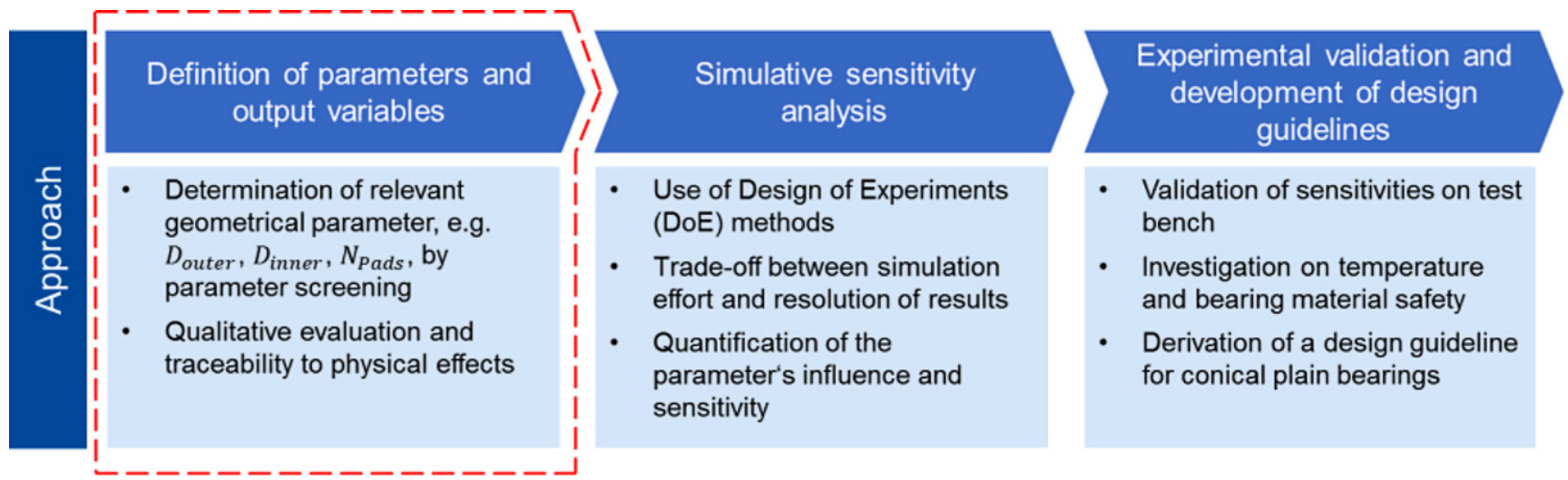

Fig. 10 Methodology for the development of a design guideline for conical plain bearings

tioned due to the high efficiency for a Plackett-Burman test field, the main effects are confounded with two-way interactions. For a more detailed analysis, further investigations with a more detailed test field are necessary.

\section{Conclusion}

The use of segmented conical plain bearings as main bearings in wind turbines has several advantages over the use of roller bearings, such as easier maintenance, which helps to reduce the LCOE, and the ability to be scaled up for the use in future wind turbines of high power classes and with big shaft diameters. In this paper, a screening of the geometric parameters of this bearing type was performed using a Plackett-Burman test field. With this screening, the most relevant parameters and qualitatively correlations have been identified. This is a first step towards the development of a design guideline as part of the industrial application of this bearing type.

To enable a quantifiable analysis of the three-dimensional pressure distribution, key values were defined, such as the maximum pressure and the pressure area ratio. One important result of the screening is that the "global" parameters that define the size and shape of the bearing (cone angle, diameters, number of pads), show a great effect on the maximum pressure and the pressure area ratio. These are important output variables for the bearing design process, because on the one hand the strength of the bearing material must not be exceeded, but at the same time the pressure area ratio and thus the power density should be as high as possible. In contrast, the results show that the parameters with an effect on the stiffness of the pad support structure hardly affect the maximum pressure, but the position of the maximum pressure and the pressure area ratio. With an intelligent combination of these parameters, the maximum pressure can be shifted from the outer edge 
further to the center of the pad, which reduces the risk of edge loading and leads to a more even load distribution on the pad.

\section{Outlook}

The parameter screening and its results shown in this paper can be considered as a first step towards the development of a design guideline for conical plain bearings. An approach to reach this goal is shown in Fig. 10.

The first step (marked red) includes the determination of the relevant parameters by conducting a parameter screening, the definition of quantifiable key values as well as the qualitative evaluation of correlations and is content of this paper. The following step of the methodology is to perform a detailed sensitivity analysis by a larger test field than the Placket-Burman field shown here. With these results, a regression model can be fitted that also can include non-linear correlations. This is necessary due to the increased complexity and nonlinear characteristics of this bearing type that is caused by the elastic deformation of the segments. In the final step, different geometric variants of conical FlexPad bearings are tested on a test bench to validate the correlations found in the sensitivity analysis. Finally, the results of the sensitivity analysis and the experimental test, as well as investigations on temperature and bearing material safety are incorporated into a design guideline.

Funding The presented investigations are based on the results of the joint project "FlexPad-Development of a design methodology for an innovative bearing concept", promoted by the German Federal Ministry for Economic Affairs and Energy (grant ID 03EE2002B). The Authors would like to thank the German Federal Ministry for Economic Affairs and Energy for funding the "FlexPad" project. In addition, the authors would like to thank their project partners Miba Industrial Bearings Germany GmbH (Göttingen, Germany) and IST Ingenieurgesellschaft für Strukturanalyse und Tribologie mbH (Aachen, Germany) for the excellent cooperation and support.

\section{Supported by:}

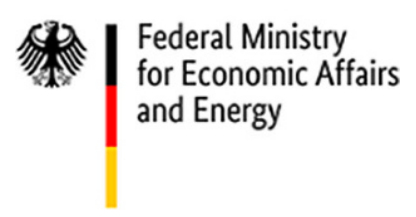

on the basis of a decision by the German Bundestag
Funding Open Access funding enabled and organized by Projekt DEAL.

Open Access This article is licensed under a Creative Commons Attribution 4.0 International License, which permits use, sharing, adaptation, distribution and reproduction in any medium or format, as long as you give appropriate credit to the original author(s) and the source, provide a link to the Creative Commons licence, and indicate if changes were made. The images or other third party material in this article are included in the article's Creative Commons licence, unless indicated otherwise in a credit line to the material. If material is not included in the article's Creative Commons licence and your intended use is not permitted by statutory regulation or exceeds the permitted use, you will need to obtain permission directly from the copyright holder. To view a copy of this licence, visit http://creativecommons.org/licenses/by/4. $0 \%$

\section{References}

1. GE Renewable Energy Haliade-X $12 \mathrm{MW}$ offshore wind turbine platform. https://www.ge.com/renewableenergy/wind-energy/ offshore-wind/haliade-x-offshore-turbine. Accessed 5 Nov 2020

2. Windkraft-Journal Siemens Gamesa bringt $15 \mathrm{MW}$ DirektantriebsOffshore-Turbine mit Power-Boost-Funktion auf den Markt. https:// www.windkraft-journal.de/2020/05/19/siemens-gamesa-bringt15-mw-direktantrieb-offshore-turbine-mit-power-boost-funktionauf-den-markt/148498. Accessed 5 Nov 2020

3. Myhr A, Bjerkseter C, Ågotnes A, Nygaard TA (2014) Levelised cost of energy for offshore floating wind turbines in a life cycle perspective. Renew Energy 66:714-728. https://doi.org/10.1016/j. renene.2014.01.017

4. Lang J, Knoll G, Hölzl J, Schröder T, Bosse D (2019) EHL simulations of hydrodynamic bearings in wind turbines. In: Conference for Wind Power Drives, pp 483-494

5. Schröder T, Jacobs G, Rolink A, Bosse D (2019) “FlexPad"-Innovative conical sliding bearing for the main shaft of wind turbines. J Phys Conf Ser 1222:12026. https://doi.org/10.1088/1742-6596/ $1222 / 1 / 012026$

6. Hölzl J, Schröder T, Rolink A (2018) Innovative Lagerkonzepte und neue Gleitlagerwerkstoffe für den Antriebsstrang von Windenergieanlagen. In: 3. VDI-Fachkonferenz Schadensmechanismen an Lagern

7. Bobzin K, Wietheger W, Jacobs G, Bosse D, Schröder T, Rolink A (2020) Thermally sprayed coatings for highly stressed sliding bearings. Wear 203415:458-459. https://doi.org/10.1016/j.wear.2020. 203415

8. Thomsen K, Klit P (2012) Improvement of journal bearing operation at heavy misalignment using bearing flexibility and compliant liners. Proc Inst Mech Eng Part J 226(8):651-660. https://doi.org/ 10.1177/1350650112439372

9. Witter D, Schelenz R, Jacobs G (2011) Simulation hochbelasteter, langsam drehender Radialgleitlager im Mischreibungsbereich unter Berücksichtigung elastischer Verformung und Verschleiß. In: VDIBerichte 2147 - Gleit- und Wälzlagerungen, pp 159-171

10. Plackett RL, Burmann JP (1946) The design of optimal multifactorial experiments. Biometrika 33(4):305-325. https://doi.org/10. 1093/biomet/33.4.305

11. Siebertz K, van Bebber D, Hochkirchen T (2017) Statistische Versuchsplanung. Springer, Berlin, Heidelberg 